\title{
Reflections on Problems and Countermeasures on Vehicle Technology Management of Transport Enterprise

\author{
Ying $\mathrm{Du}^{1, \mathrm{a}}$, Jianhua Zhang ${ }^{1, \mathrm{~b}}$ and $\mathrm{He}$ Wang $^{1, \mathrm{c}}$ \\ ${ }^{1}$ College of Automobile \& Architectural Engineering, Beihua University, China

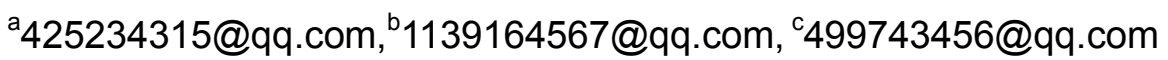

Keywords: Transportation enterprises; Vehicle technical management; Problem; Method; Measures

\begin{abstract}
With the rapid growth of china's national economy, china's road transport industry has been rapid development, as one of the three key elements of traffic management, the important role of vehicle technology management in road transportation management. This paper analyzes the transportation enterprises in the vehicle technology management in a number of problems, and put forward the methods and measures to solve these problems.
\end{abstract}

\section{Introduction}

In recent years, As one of the three elements of traffic management vehicle technology management in the road transport management in the increasingly prominent position, but the traditional vehicle technology management model there are many drawbacks, hinder the prosperity and development of road transport. This article on strengthening and improving the transportation enterprise vehicle technology management to talk about their views.

\section{Overview of Vehicle Technology Management}

Vehicle technology management, refers to the vehicle from the selection of procurement to the disposal of the whole process of comprehensive management.

\section{Problems in the Current Technical Management of Vehicle Transportation in Transportation Enterprises}

Vehicle Maintenance Awareness is Weak, not on Schedule for Secondary Maintenance, Two Maintenance Practices Strict Implementation. In the transport enterprises, there is the vehicle " attention-use, light maintenance" concept, cost savings, often after the vehicle problems to repair, repair instead of maintenance.

Maintain the Quality of the Regulatory Work Flow in the Form, Hinder the Vehicle Technology Management System to Further Implement. As a third party after the maintenance of quality assessment - comprehensive performance testing station, most of which are profitable economic entities, they attach importance to economic efficiency, disdain the quality of testing.

Heavy Enterprise Economic Benefits, Light Vehicle Technology Management, an Increase of Technical Management of the Difficulty. Subject to the constraints of market economy conditions, some transport companies face one-sided pursuit of short-term economic benefits, ignore the vehicle technology management, lack of necessary measures and means for vehicle technology management, relax the daily maintenance and management of the driver's education, resulting in a decline in vehicle technology[1-3].

Maintenance Personnel Training is not in Place, Maintenance Team Quality Decline. In recent years, some transport companies have less investment in maintenance personnel, leading to maintenance staff cultural quality and technical quality is low, the structure and performance of the vehicle do not understand, unskilled maintenance technology, the enterprise lacks the necessary detection and diagnosis equipment, can not guarantee the quality of vehicle maintenance.

Ignore the Management of Vehicle Technical Files. Some transport companies do not attach 
importance to the establishment of vehicle technology files, or even no technical files, some transport enterprises in order to cope with the relevant departments of the inspection, the preparation of some testing and maintenance records, resulting in the lack of authenticity of the vehicle technical files, resulting in enterprises can not grasp the use of vehicle technology and maintenance.

\section{Strengthen the Transport Enterprise Vehicle Technology Management should Start from the following Aspects}

Improve the Vehicle Technology Management System, a Clear Vehicle Technology Management in the Industry Management of the Basic Role. The management of vehicle technology should adhere to the principle of combining prevention and technology and economy.

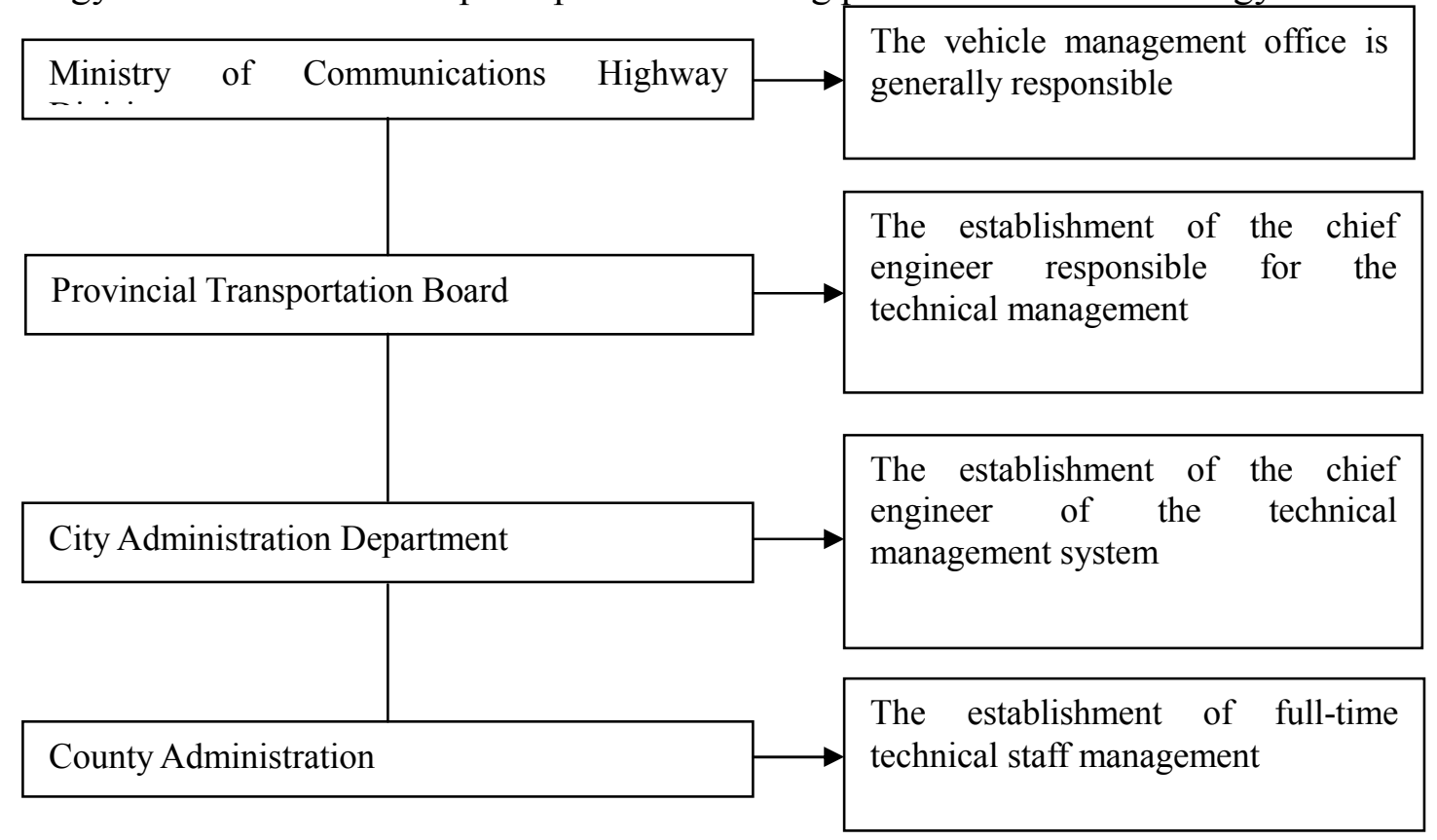

Figure 1. The whole industry vehicle technology management system

All levels of transport management and transportation management personnel should pay attention to vehicle technology management[4-6]. At present, the vast majority of local transport management institutions at all levels have a dedicated organization for vehicle technology management. In the road transport authority, at the corresponding set of functional agencies, clear responsibilities, to implement the people, timely detection of problems, timely solve the problem, to ensure that the vehicle technology in good condition, the full implementation of vehicle technology management. The whole industry vehicle technology management system is shown in Fig. 1.

Transport Business Leaders should Attach Importance to Vehicle Technology Management, Strengthen the Transport Enterprises of the Two Maintenance Work, Improve and Implement the Vehicle Two Maintenance System. In order to protect people's lives and property, in order to economic efficiency of enterprises, transport enterprises must adhere to the mandatory maintenance, for those who do not carry out secondary maintenance overdue vehicles, enterprise technical management departments have the right to deduct the maintenance of the vehicle profits, and ordered its mandatory maintain[7,8]. Do not carry out secondary maintenance of the vehicle scheduling is not deployed in its operation, while transport companies have a complete organization and management agencies and a clear job responsibility system, so that every link, each process has a complete record in order to accurately reflect Vehicle technical conditions, enhance the sense of responsibility of workers, reduce the interference of human factors. Jilin City, a passenger group began to operate, the first implementation of the talent strategy for the province's selection of technology on the top management and engineering and technical personnel, respectively, as the group key positions responsible person. Formed a general manager as the core of the leadership of 
the vehicle technology management system. Group vehicle technology management system is shown in Fig. 2.

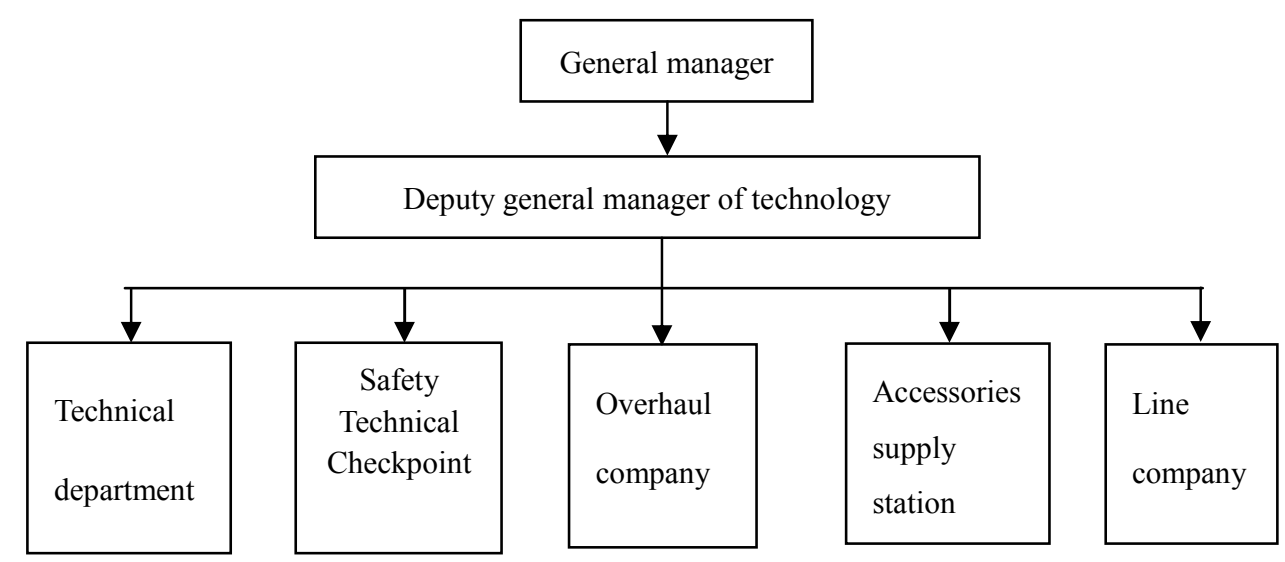

Figure 2. Group vehicle technology management system

Strengthen the Maintenance of the Two Enterprises to Maintain Quality Management, Pay Attention to Enterprise Personnel Training, Improve Management, Use Vehicle Technology Management Software System. Strengthen the maintenance of workers technical training and business operation technology, so that card holders to reduce the repair rate; maintenance companies have planned to purchase the necessary maintenance of secondary testing equipment to improve the quality of maintenance; maintenance companies to train or absorb a number of Have a higher cultural accomplishment and technical quality of the maintenance staff, in particular, should do a good job training of young maintenance personnel[9,10]. For the larger number of transport enterprises, the traditional handwritten forms can not meet the increasingly complex management needs, which requires the use of computers to establish vehicle management procedures, thereby enhancing efficiency and reduce flaws. At present, the Group has adopted the Excel 2007 electronic form to establish the vehicle technology management software system, the company's vehicle technology management information related to registration.

Increase the Training of Managers and Drivers, and Improve the Quality of Management and Practitioners. Regularly conduct training on the structure, performance, quality of work, maintenance process, general fault diagnosis and elimination of all kinds of vehicles, and regularly carry out knowledge of new technologies, new processes, new materials and new equipment for industry executives Of the study, the selection of a strong sense of business, proficient in technology, good management of personnel engaged in vehicle technology management work, transport enterprises at the grassroots level vehicle managers and managers in charge of vehicle technology management, the implementation of certification posts and annual inspection system. Strengthen the driver to maintain a good sense of vehicle technology in good condition, combined with "operating vehicle qualification certificate" to train the driver to strengthen the driver of the relevant industry regulations and new knowledge of new technology learning.

\section{Conclusion}

For the transport enterprise vehicle technology management, a direct impact on the normal use of vehicles and occupants of life and property safety, its importance is self-evident. Therefore, we must analyze the existing problems in vehicle technology management, and targeted to improve and improve the measures to be able to truly achieve vehicle technology management objectives to ensure the normal use of vehicles.

\section{References}

[1] L.Q. Ding: China Science and Technology Investment, Vol. 23 (2014) No.15, p.564.

[2] J.F. Xu: Industrial \& Science Tribune, Vol. 13 (2014) No.15, p.69. (In Chinese) 
[3] Automotive electronic health files on http://auto.inf-technology.com/

[4] C.M. Sun: Technology and Economic Guide, Vol. 12 (2016) No.20, p.216.(In Chinese)

[5] H.J. Chen: Car use base(Machinery Industry Press, Switzerland 2011)

[6] C. Sun: JTechnical Management, Vol. 13 (2015) No.2, p.57.(In Chinese)

[7] W. Yao: Northern Economy and Trade, Vol. 24 (2015) No.6, p.216.(In Chinese)

[8] Vehicle technology management on https://wenku.baidu.com/view

[9] G.F. Niu: Manager' Journal, Vol. 8 (2015) No.28, p.107.(In Chinese)

[10]E.J. Yang: Ability and Wisdom, Vol. 36 (2014) No.14, p.291. (In Chinese) 